\title{
Job variation in Australian advanced training in neurology
}

\author{
C. J. Lueck, ${ }^{1}$ J. Morris ${ }^{2}$ and E. Pepper ${ }^{2}$ \\ ${ }^{1}$ Department of Neurology, The Canberra Hospital and Australian National University Medical School, Canberra, Australian Capital Territory and \\ ${ }^{2}$ Department of Neurology, Westmead Hospital, Sydney, New South Wales, Australia
}

\author{
Key words \\ physician training, education, neurology, \\ questionnaire survey.

\section{Correspondence The Canberra Hospital, PO Box 11, Woden, ACT 2606, Australia. \\ Email: christian.lueck@act.gov.au} \\ Christian J. Lueck, Department of Neurology,
}

Received 25 July 2007; accepted 12 October 2007.

doi:10.1111/j.1445-5994.2007.01584.x

\begin{abstract}
Background: Like training posts in other medical specialties, many of the 38 Australian core training posts in neurology have been criticized over a variety of issues relating to the quality of training provided. These issues include excessive hours of work (often related to understaffing), high inpatient workload and inadequate exposure to outpatients and/or specialist procedures. To examine these issues, we conducted an audit of Australian advanced training posts in neurology to obtain baseline data.

Methods: Two questionnaires were sent out, one to each head of department and another to the advanced trainees currently in post, requesting information about each of the training posts. The posts were compared with each other on an individual basis and by grouping them into three geographically related groups. Results: There was complete ascertainment and a wide variation in most of the measures examined, including inpatient and ward consult numbers, staffing levels, general neurological and specialist outpatient clinic exposure and overtime requirements. Exposure to neurophysiology clinics and training in electroencephalogram was more uniform.

Conclusion: Core advanced training jobs in neurology vary considerably across Australia, largely for historical reasons. This situation is suboptimal for many reasons. Training jobs ideally need to be modified to take into account the changing needs of trainees rather than just the service requirements of the various departments, but there are many resource issues involved in achieving this.
\end{abstract}

\section{Introduction}

In Australia, advanced training in medical specialties occurs following a period of basic training and successful completion of the Fellow Royal Australasian College of Physicians (FRACP) part 1 examination. ${ }^{1}$ Many advanced training posts in various specialties have been criticized over a variety of issues relating to the quality of training provided. These issues include excessive hours of work (often related to understaffing), high inpatient workload and inadequate exposure to outpatients and/or specialist procedures.

Funding: None

Potential conflicts of interest: None
The Australian neurological advanced training programme currently comprises two 'core' years working as a specialist neurological registrar in accredited jobs, followed by an 'elective' year, which is somewhat more flexible. ${ }^{2}$ During this year, trainees can opt for either specialist clinical attachments or a dedicated year of neurophysiology, or they can travel abroad to obtain further neurological experience internationally. As with other specialties, many neurological training posts have been subjected to the above criticisms.

By way of further background, there is considerable international variation in the length of neurological training from one country to another. ${ }^{3}$ A recent European survey showed that the number of years required to become a trained neurologist ranged from two (Georgia) to seven (Denmark), with most of the countries requiring 
4 or 5 years. ${ }^{4}$ The specialist training programme for Neurology in Britain ${ }^{5}$ and the residency programme in the USA $^{6}$ are currently of 4 years' duration. Heterogeneity of training positions within countries has occasionally been commented on in various parts of the world, ${ }^{3,7,8}$ but we are only aware of one previous audit of neurology training programmes in the published work. ${ }^{9}$ This study surveyed various aspects of neurological training posts in Italy: ascertainment was incomplete, but the authors were able to show considerable variation between jobs among those who replied. The authors concluded that 'greater emphasis should be placed on competency as the goal of training, rather than merely in providing training experience'.

At the time of this study there were 38 posts accredited for core training in neurology in Australia. Accordingly, we conducted an audit of these posts to obtain baseline data with a view to assessing how advanced training in neurology might best be optimized in Australia.

\section{Methods}

A questionnaire (Appendix I) was circulated to the Heads of Department (HoDs) of the 28 neurology departments in Australia that were able to offer core training positions in neurology in 2006. The questionnaire contained 26 questions about hospital demographics (catchment population, size of hospital, number of neurology beds, access to neurosurgery and neurophysiology), staffing (numbers of consultants and neurology junior staff), clinic exposure and overtime. Queries were resolved by subsequent direct communication with HoDs as necessary.

A second questionnaire (Appendix II) was then circulated to Australian advanced trainees in neurology in March 2007. This was a separate questionnaire that contained four additional questions relating to workload (inpatient and consult numbers), clinic exposure, neurophysiology training and overtime. Missing data and queries were resolved by subsequent communication with advanced trainees as necessary.

Some additional demographic information was obtained by telephoning hospital publicity departments.

The areas of interest could be grouped under six different headings:

1 Demographics. To try to assess breadth of exposure, the hospitals were asked to provide information in relation to catchment population, size of hospital (number of beds), average number of neurology inpatients and whether neurosurgery and neurophysiology were available on site. 2 Staffing. HoDs were asked to provide information about the full-time equivalent (FTE) number of neurologists in their department and the number of junior neurological staff. A crude assessment of junior staff support for advanced trainees was calculated by dividing the number of resident medical officers and/or interns by the total number of ward registrars (i.e. both advanced and basic trainees).

3 Ward work. The average total number of neurology inpatients was divided by the number of ward registrars to obtain a figure of the average number of inpatients looked after by advanced trainees at any one time. If training positions were organized as rotations, part of which involved inpatient cover and part of which did not, the figures were averaged across the whole year of training to allow direct comparison between jobs as many jobs did not involve such rotation. Similar calculations were made to derive the average number of weekly ward consults seen by advanced trainees.

4 Outpatient clinics. Trainees were asked to state the average number of general neurology outpatient clinics and the number of dedicated specialist neurology clinics (e.g. neurovascular, movement disorders, epilepsy and so on), which they were scheduled to attend each week during the year. Again, if the job involved a rotation, the clinics were averaged across the whole year to allow comparison between jobs. In addition, trainees were asked to list the various different subspecialties, which were 'on offer' at their hospital.

5 Neurophysiology. Trainees were asked to state the average number of nerve conduction studies/electromyography (NCS/EMG) clinics they attended each week, again averaged across the year if necessary. Similarly, trainees were asked to state the average number of electroencephalograms (EEG), which were reported by them (under supervision) each week.

6 Overtime. Trainees were asked to state the average number of hours of overtime each week in each of three categories:

- Rostered on-call for general medicine

- Rostered on-call specifically for neurology

- Unrostered overtime. Trainees were also asked whether their hospital paid their overtime claims in full

To preserve anonymity, hospitals were allocated a number that was used in any display of the results of the audit. In addition to looking at Australia as a whole, results from the 28 hospitals were grouped for purpose of comparison into three geographical areas - New South Wales (NSW)/ Australian Capital Territory, Victoria (Vic.)/Tasmania and Queensland/South Australia/Western Australia - based on the fact that the two largest groups of trainees were in NSW and Vic. and that this grouping resulted in three groups with approximately equal numbers. For every parameter, the median was derived for each group.

\section{Results}

Complete information was ascertained from all 28 neurology departments. Not all posts were filled at the time of 
the survey, but the data are presented as if the posts were all filled for the purposes of comparison. A summary of the data is presented by geographical area in Table 1. The results will be dealt with on a hospital-by-hospital basis under each of the six different headings:

1 Demographics. Officially 'declared' catchment groups ranged from 200000 to 1500000 (Fig. 1). Hospital bed numbers ranged from 300 to 975 , numbers of neurology inpatients ranged from 13 to 45 . Six of 28 hospitals ( $21 \%$ ) had limited or no neurosurgery on site. All hospitals had neurophysiology on site.

2 Staffing. Consultant numbers ranged from 1.8 to 7.4 FTE, total neurology junior staff numbers ranged from 1.8 to 9 (including Fellows and research registrars) (Fig. 2). There were between 1 and 3 advanced trainees per department and the intern or resident medical officer (RMO) support for each advanced trainee ranged from 0.33 to 2 .
3 Ward work. Average numbers of inpatients per advanced trainee ranged from 4 to 25 (median 11) and the average number of consults per week ranged from 4 to 12.5 (median 7.5) (Fig. 3).

4 Outpatient clinics. The average number of general neurology clinics per week ranged from 0.5 to 4 , the number of specialist clinics from 0 to 3 and the total number of clinics per week from 1 to 5 (Fig. 4). Details of the dedicated specialist clinics available are given in Table 2.

5 Neurophysiology exposure. The number of EEG reported under supervision ranged from 0 to 15 (median 5) and the number of weekly NCS/EMG clinics ranged from 0.25 to 2 (median 1) (Fig. 5).

6 Overtime. Twelve departments rostered trainees to neurology on-call (range $21.3-80 \mathrm{~h} /$ week); the remaining 16 departments rostered their trainees to general medical on-call (range 1.5-19 h/week) (Fig. 6). Average unrostered

Table 1 Summary of questionnaire results grouped according to geographical area

\begin{tabular}{|c|c|c|c|c|}
\hline & Australia & NSWIACT & Vic./Tas. & QId/SA/WA \\
\hline \multicolumn{5}{|l|}{ General } \\
\hline No. advanced trainee core positions & $38^{\dagger}$ & 13 & $14^{\dagger}$ & 11 \\
\hline No. training hospitals & $28^{\dagger}$ & 12 & $8^{\dagger}$ & 8 \\
\hline No. hospitals providing data & 28 & 12 & 8 & 8 \\
\hline \multicolumn{5}{|l|}{ Hospital statistics } \\
\hline $\begin{array}{l}\text { Draining population of training hospital, } \\
\text { median (range) }(\times 1000)\end{array}$ & $700(200-3000)$ & $600(225-1500)$ & $775(300-3000)$ & $650(200-1250)$ \\
\hline $\begin{array}{l}\text { No. inpatient beds in training hospital, } \\
\text { median (range) }(\times 1000)\end{array}$ & $500(300-975)$ & $510(300-975)$ & $390(330-930)$ & $550(360-900)$ \\
\hline $\begin{array}{l}\text { Average number of neurology inpatients } \\
\text { including stroke, median (range) }\end{array}$ & $20(13-45)$ & $20(14-45)$ & $24.5(18-35)$ & $19(13-40)$ \\
\hline \multicolumn{5}{|l|}{ Staffing levels } \\
\hline $\begin{array}{l}\text { No. neurology consultants (FTE) per hospital, } \\
\text { median (range) }\end{array}$ & $4.0(1.8-7.4)$ & $5.1(1.8-7.4)$ & $3.7(2.0-6.0)$ & $3.0(1.8-6.5)$ \\
\hline Total no. neurology junior staff, median (range) & $5.0(1.8-8.0)$ & $5.0(3.5-6.0)$ & $6.0(2.0-8.0)$ & $4.0(1.8-7.0)$ \\
\hline No. neurology advanced trainees median (range) & $1(1-3)$ & $1(1-2)$ & $2(1-3)$ & $1(1-2)$ \\
\hline No. RMOs or interns per advanced trainee, median (range) & $0.75(0.33-2.0)$ & $0.88(0.33-1.5)$ & $0.88(0.5-1.0)$ & $0.68(0.33-2.0)$ \\
\hline \multicolumn{5}{|l|}{ Ward work } \\
\hline $\begin{array}{l}\text { Average no. inpatients per advanced trainee, } \\
\text { median (range) }\end{array}$ & $11.0(4.0-25.0)$ & $11.8(6.0-20.0)$ & $10.5(4.0-25.0)$ & $11.5(5.5-25.0)$ \\
\hline Average no. weekly consults, median (range) & $7.5(4.0-12.5)$ & $8.3(5.0-12.0)$ & $7.5(4.0-12.5)$ & $9.8(7.5-12.5)$ \\
\hline \multicolumn{5}{|l|}{ Outpatient clinics } \\
\hline No. general neurology clinics/week, median (range) & $1.0(0.5-4.0)$ & $1.0(0.5-2.5)$ & $1.0(0.5-2.0)$ & $2.0(1.0-4.0)$ \\
\hline No. specialist clinics/week, median (range) & $1.0(0.0-3.0)$ & $0.4(0.0-3.0)$ & $1.0(0.0-1.5)$ & $1.0(0.0-1.5)$ \\
\hline \multicolumn{5}{|l|}{ Neurophysiology } \\
\hline $\begin{array}{l}\text { Average no. EEG reported under supervision/week, } \\
\text { median (range) }\end{array}$ & $5.0(0.0-15.0)$ & $5.0(3.0-10.0)$ & $5.0(0.0-12.5)$ & $4.8(4.0-15.0)$ \\
\hline No. teaching NCS/EMG clinics/week, median (range) & $1.0(0.25-2.0)$ & $1.0(0.5-1.5)$ & $1.0(0.25-1.5)$ & $1.0(1.0-2.0)$ \\
\hline \multicolumn{5}{|l|}{ Overtime } \\
\hline Rostered general medical on call in hours, median (range) & $2.0(0.0-19.0)$ & $5.1(0.0-12.0)$ & $0.0(0.0-0.0)$ & $1.5(0.0-19.0)$ \\
\hline Rostered neurology on call in hours, median (range) & $2.0(0.0-80.0)$ & $0.0(0.0-42.7)$ & $39.7(21.3-80.0)$ & $2.0(0.0-42.7)$ \\
\hline Average weekly overtime claim in hours, median (range) & $8.0(0.0-20.0)$ & $8.0(3.0-15.0)$ & $7.3(4.0-15.0)$ & $10.0(0.0-20.0)$ \\
\hline Average total weekly non-core hours, median (range) & $23.3(8.0-95.0)$ & $13.7(8.0-49.7)$ & $46.1(26.3-95)$ & $20.3(7.0-52.7)$ \\
\hline
\end{tabular}

${ }^{\dagger}$ Excluding Hobart. ACT, Australian Capital Territory; EEG, electroencephalogram; EMG, electromyography; FTE, full time equivalent; NCS, nerve conduction studies; NSW, New South Wales; QId, Queensland; RMO, resident medical officer; SA, South Australia; Tas., Tasmania; Vic., Victoria; WA, Western Australia. 
Lueck et al.

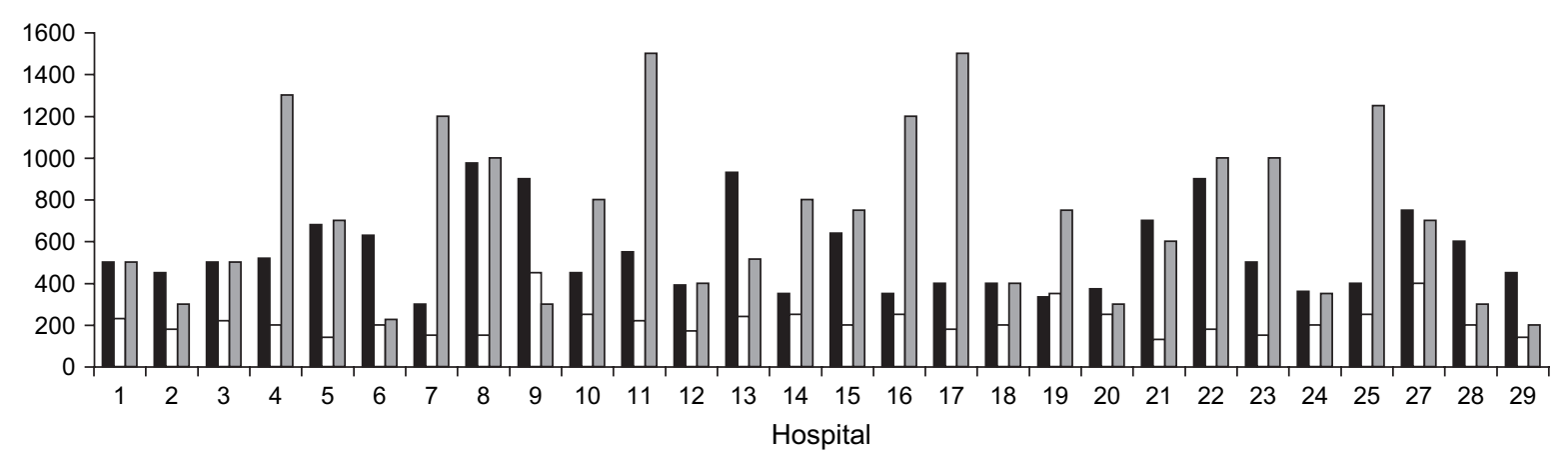

Figure 1 Hospital demographics (sorted by hospital). $\square$, hospital beds; $\square$, neurology beds ( $\times 10)$; $\square$, catchment population (/100).

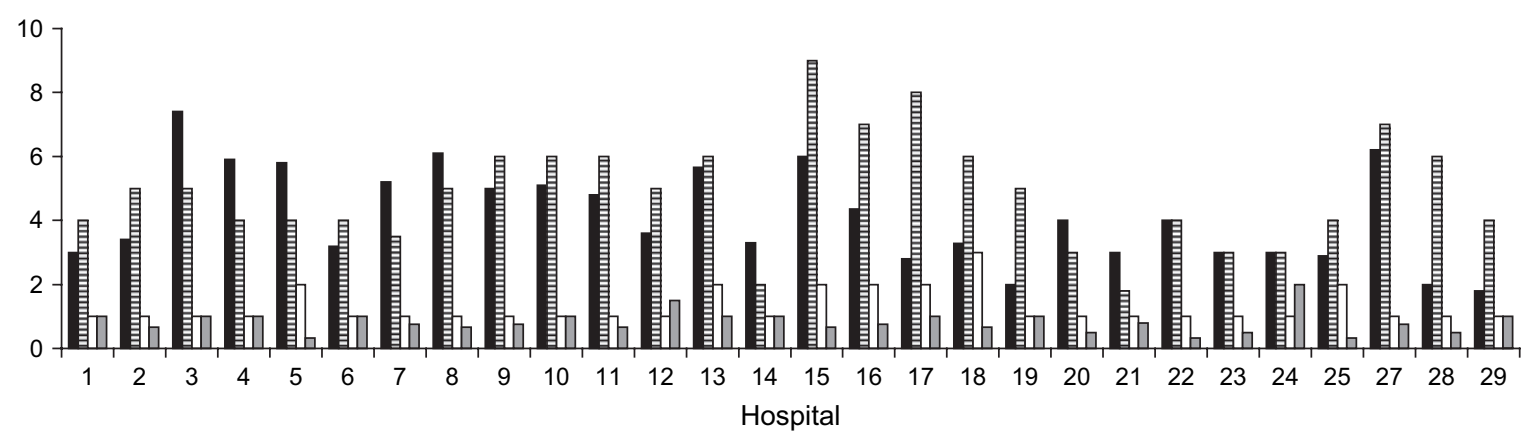

Figure 2 Departmental staffing (sorted by hospital). $\square$, consultant full time equivalent; 且, total neurology junior staff; $\square$, advanced trainees; $\square$, resident medical officer : trainee ratio.

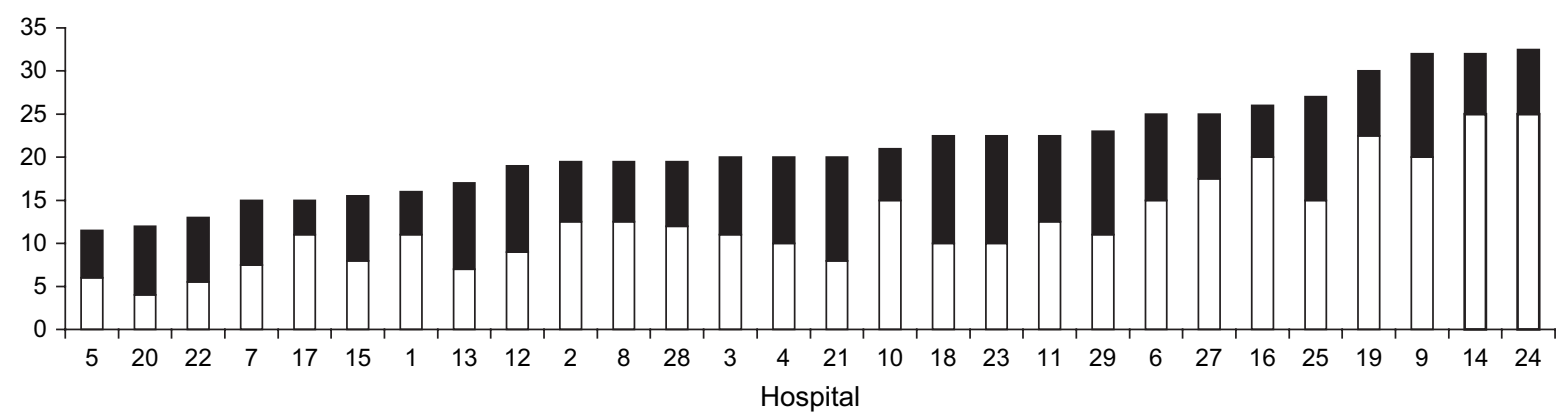

Figure 3 Average number of inpatients/advanced trainee and average weekly consults (sorted according to total inpatients + consults). $\square$, inpatients; a, consults.

overtime ranged from 0 to $20 \mathrm{~h} /$ week. Twenty of the 28 departments paid all overtime claims, 8 did not.

\section{Interhospital comparisons}

With the exception of overtime arrangements, the 'median' neurology core training job was fairly consistent across the three geographical areas and Australia as a whole. However, there was considerable variation between individual neurology core training jobs.

The most obvious difference related to out-of-hours on-call work. Twenty-two of the 38 core jobs (58\%) involved neurology on-call outside standard working hours (median $40 \mathrm{~h}$ (range 21-80 h) per week) whereas the remaining $16(42 \%)$ did not. Other wideranging aspects of core training jobs included 


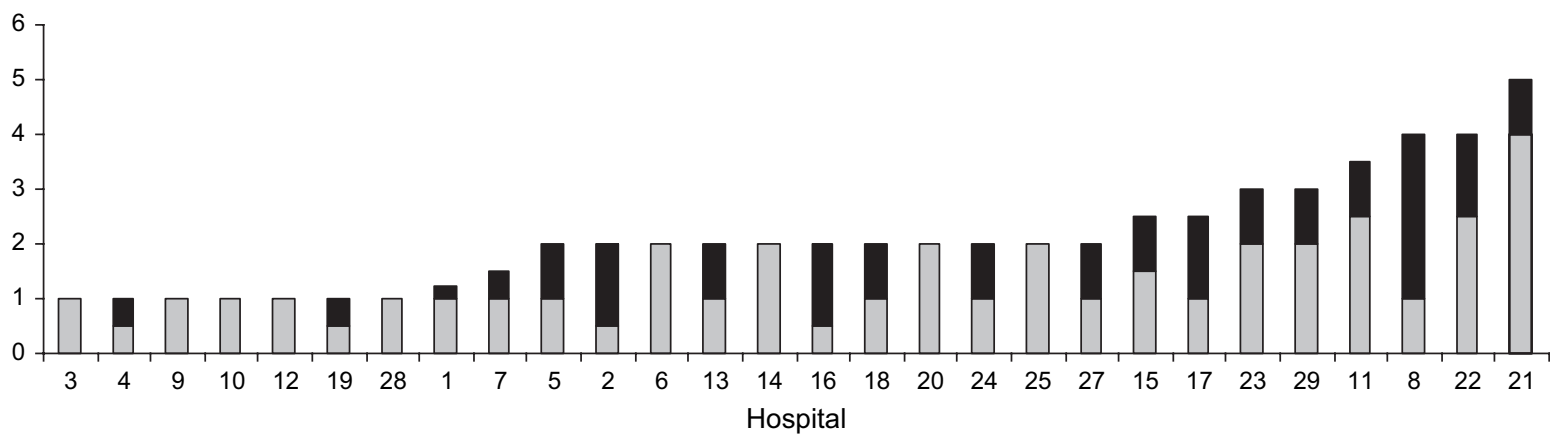

Figure 4 Number of weekly clinics. $\square$, general neurology; $\square$, specialist.

- The RMO:registrar ratio (range 0.33-2.0)

- The number of inpatients per advanced trainee (range 4-25)

- The number of ward consults/week (range 5-12.5)

- The number of specialist clinics/week (range 0-3)

- The range of specialist clinics offered. Inner city hospitals offered an average of $2.8 \pm 1.8$ options per job (range $0-6$ ) whereas more 'peripheral' hospitals could only offer an average of $1.2 \pm 1.5$ options (range $0-5$ )

- The average number of EEG reported under supervision (range 0-15)

- Unrostered overtime varied considerably from 0 to $20 \mathrm{~h} /$ week.

Aspects with a greater degree of uniformity included

- The number of general neurological clinics/week; 33/38 trainees $(79 \%)$ attended at least one clinic per week (range $0.5-4.0)$

- The number of NCS/EMG clinics; $32 / 38$ trainees (84\%) attended at least one clinic/week (range 0.25-2.0).

\section{Discussion}

In summary, there was enormous variation between the 38 individual Australian core training jobs in neurology in almost all areas studied. The reasons for this variability are understandable from an historical perspective in that the various training posts have evolved over time and each one will have been individualized to the service needs of the host hospital at the time it was created. Granted that the funding (i.e. salary) of these posts is generally related to provision of service, this fact obviously needs to be taken into consideration when suggesting possible changes to the jobs to try to improve them. However, if Australia is to be assured of a continuing supply of appropriately trained neurologists, the various neurological advanced training jobs need ultimately to be geared to the training requirements of the trainees themselves rather than to the service needs of individual departments. The immense variation between jobs suggests that this is currently not the case.
A certain amount of variability between jobs is probably a good thing as rotation from one hospital to another during training will thereby generate a broader exposure - the question is, how much variation is needed/acceptable? Space does not permit a detailed discussion of every different aspect studied and reported here. However, one or two specific areas deserve further comment.

The most obvious difference between training jobs relates to rostered out-of-hours on-call. A little more than half the jobs required trainees to be on-call for neurology, whereas the remainder had their advanced trainees participate in the general medical on-call roster. Once trained, neurologists will generally be expected to provide an outof-hours neurology on-call service rather than a medical on-call service, although a small number of neurologists do provide both. Overall, it would seem that training jobs that include neurology on-call out of hours are more relevant, but it is not unreasonable to continue with a certain amount of general medical on-call if this can be arranged in addition. Jobs without any neurology on call are less desirable, but extracting the current neurology trainees from their existing general medical on-call commitments would (i) require additional funding, (ii) disadvantage the other doctors left behind on the general medical roster and (iii) possibly increase the duration of time required for neurology training. Thus, modifying neurological advanced training to achieve national uniformity would probably require considerable additional funding.

In addition to providing out-of-hours on-call cover for hospitals, the working life of most neurologists is principally outpatient based. The characteristics of the outpatient groups seen are obviously considerably different from those of the inpatients - in Australian hospitals, the large majority of neurological inpatients have suffered from stroke. In outpatients, the patient clientèle are more likely to have diagnoses of epilepsy, headache, movement disorders, multiple sclerosis and so on, very few of which are severe enough for the patient to be admitted to hospital. Thus, to train neurologists to do the job they will 
Lueck et al.

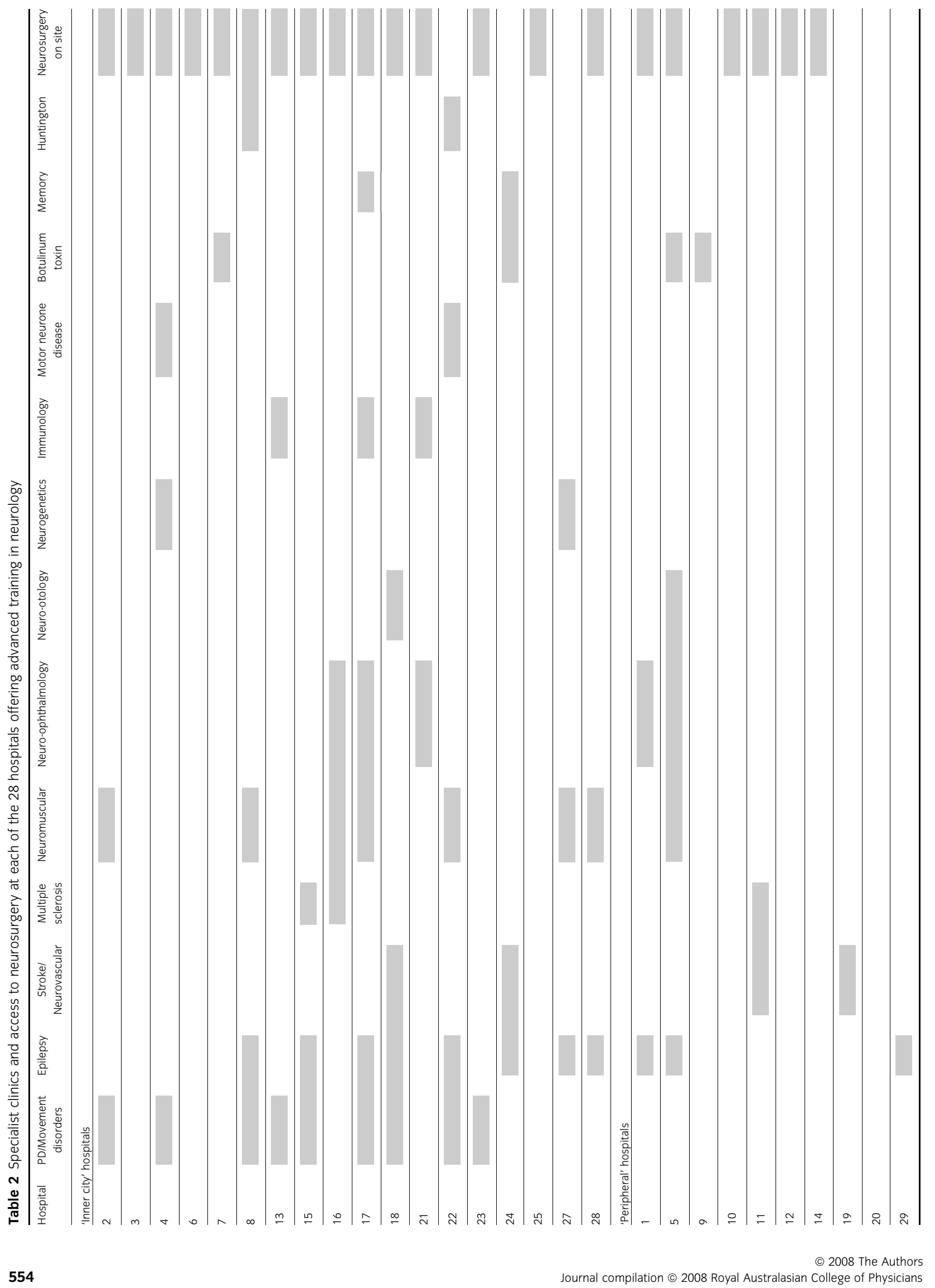




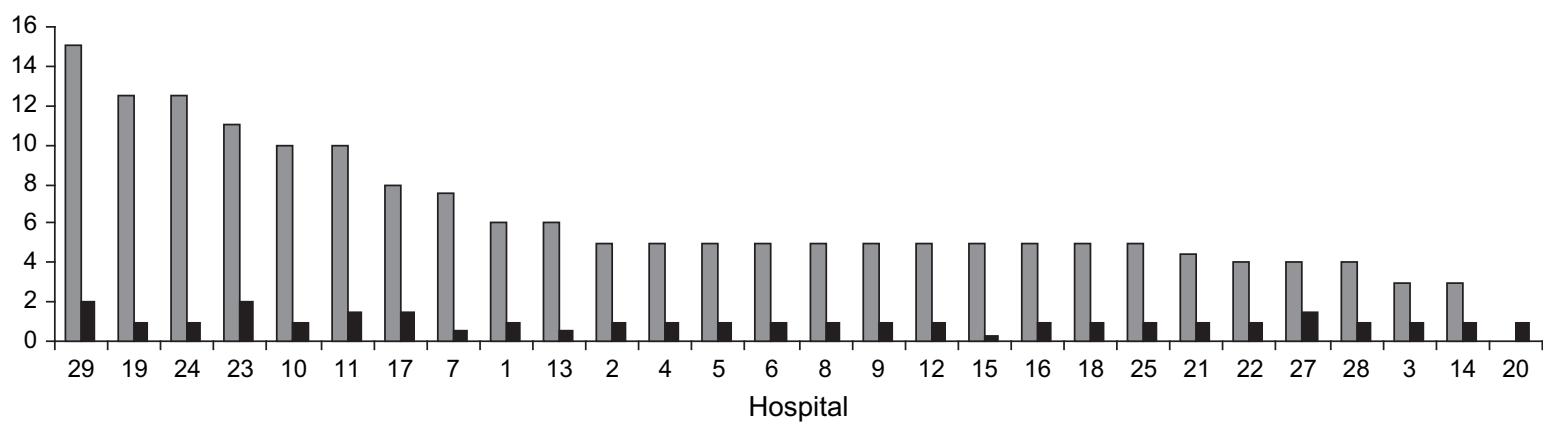

Figure 5 Neurophysiology exposure. $\square$, electroencephalogram per week; $\boldsymbol{\square}$, electromyography clinics per week.

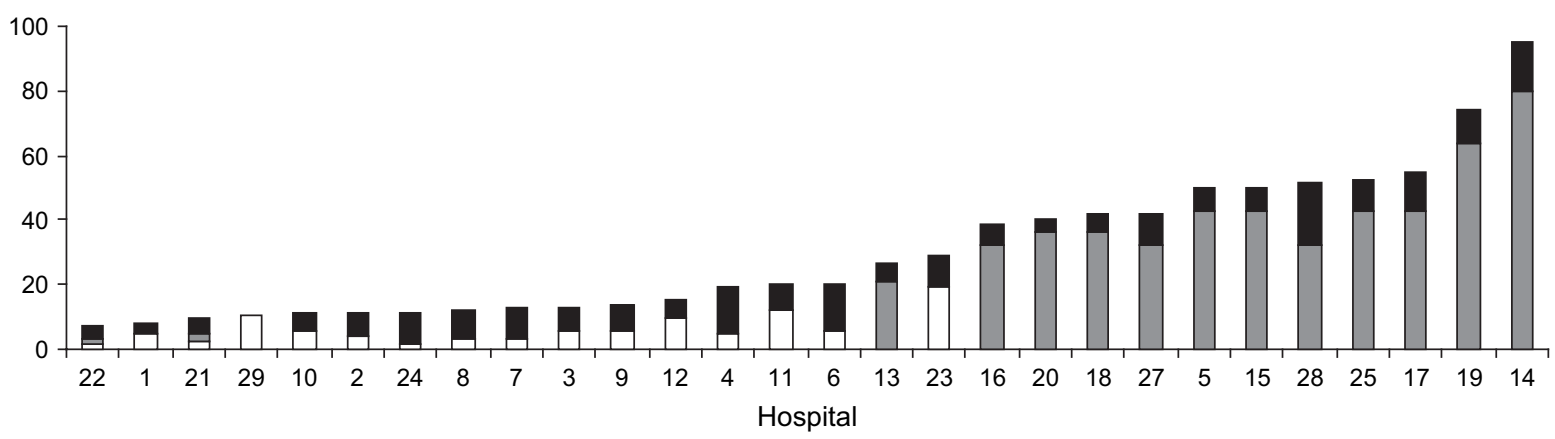

Figure 6 Rostered and unrostered overtime (h/week). $\square$, general medical on call; $\square$, neurology on call; $\square$, unrostered overtime.

eventually have to do as consultants, trainees need to have as much outpatient exposure as possible. Our survey indicated that most of the jobs offered at least one general neurology clinic and one specialist neurology clinic per week, but this may not be adequate to obtain exposure to all the different problems seen in an outpatient setting in just two core years. With respect to exposure to specialist clinics, the type of specialty found is, to some extent, a lottery depending on which areas are offered by the training hospital.

At a time when the organization and supervision of subspecialty training are being reviewed by the Royal Australasian College of Physicians (RACP) and certain subspecialty colleges, the Australian medical workforce is also changing: more graduates and women are entering medical schools than ever before. ${ }^{10}$ Subspecialty training needs to become more flexible to accommodate these changes, including increasing availability of, and access to, part-time training. Outpatient activity is ideally suited to part-time work and one advantage of increasing the amount of outpatient exposure is that training programmes might find themselves better able to accommodate part-time trainees as and when the need arises.

What about other countries? As above, the specialist training programme for Neurology in Britain ${ }^{5}$ and the residency programme in the USA ${ }^{6}$ are 4 years long, compared with 3 years in Australia. (Incidentally, the minimum requirement for prior exposure to postinternship training in internal medicine in the three countries is 3 years, 0 years, and 3 years, respectively.) In Britain, most trainees attend at least three outpatient clinics per week during their training and so will have obtained considerably more outpatient exposure than their Australian counterparts by the time they take up their consultant positions.

As the Australian advanced training jobs have evolved out of the service needs of the various departments, it is not easy to modify the outpatient exposure of existing incumbents - to do so would take the registrars away from other duties, usually without any obvious cover to provide backfill. Essentially, therefore, this is a funding issue greater funds will have to be allocated to neurology training to relieve the advanced trainee posts of a certain proportion of their ward-based activities so as to allow trainees to attend more outpatient clinics.

A similar argument applies to exposure to other, related, clinical specialty units such as paediatric neurology, rehabilitation, neuropathology, neurophysiology and so on. In the USA, neurology trainees spend time specifically and formally attached to these units. ${ }^{6}$ Trainees in Australia are 
generally too heavily committed to their existing schedules to allow such attachments to take place. Again, one (and perhaps the only) solution to this is greater funding of the neurology junior staff to permit an increase in overall numbers and so free up time for advanced trainees to rotate to other specialties.

\section{Conclusion}

Much work is clearly required if neurology training in Australia is to become more standardized, first in terms of setting up a National Curriculum with minimum standards of core competencies and, second, in terms of modifying existing training jobs so that they are directed to the requirements of the trainees. There are several possible interim measures that could be taken to improve the existing situation without cost implications, including deliberate 'matching' of jobs to 'even out' an individual trainee's exposure during the two core years. One way in which this could be achieved is to set up formal rotations. At the end of the day, however, greater allocation of funds to expand manpower will probably be required. The Australian and New Zealand Association of Neurologists has received a proposal to set up a committee to focus on improving standardization of neurological training in conjunction with the RACP. It is to be hoped that if a repeat survey were to be carried out in a few years' time it would yield a much greater level of consistency across individual jobs.

\section{Acknowledgements}

The authors would like to thank the busy Heads of Departments and Advanced Trainees who took time to fill in the questionnaires and answer subsequent questions, as well as the anonymous reviewers who offered helpful comments.

\section{References}

1 Royal Australasian College of Physicians. Eligibility for advanced training. September 2003 [cited 2007 Jul 2]; Available from URL: http://www.racp.edu.au/training/ adult2003/advanced/general/intro.htm\#entry

2 Australian and New Zealand Association of Neurologists. Advanced training in neurology. [cited 2007 Jul 2]; Available from URL: http://www.anzan.org.au/ neurologytraining/advancedtraining.asp

3 Hooker J, Eccher M, Lakshminarayan K, Souza-Lima FC, Rejdak K, Kwiecinski H et al. Neurology training around the world (forum). Lancet Neurol 2003; 2: 572-9.

4 Pontes C. EFNS task force on postgraduate neurological training. Survey of the current situation of postgraduate neurological training in Europe. Eur J Neurol 2001; 8: 381-4.

5 Higher Specialty Training for Neurology. British Joint Committee on Higher Medical Training. September 2005 [cited 2007 Jul 2]; Available from URL: http://www.jrcptb.org. uk/Specialty/Documents/Neurology\%20Curriculum.pdf

6 United States Program Requirements for Residency Training in Neurology. June 2004 [cited 2007 Jul 2]; Available from URL: http://www.acgme.org/acWebsite/downloads/ RRC_progReq/180pr105.pdf

7 Facheris M, Mancuso M, Scaravilli T, Bonifati DM. Neurology residency training in Europe: an Italian perspective. Lancet Neurol 2005; 4: 258-62.

8 Mizutani T. [Postgraduate education of neurology (PGEN) in Japan] (Abstract). Rinsho Shinkeigaku 2002; 42: 1134-6.

9 Bonifati DM, Scaravilli T, Leone M, De Biasia F, Naccarato M, Ottina $\mathrm{M}$ et al. Quality or neurology residency programmes: an Italian survey. Eur J Neurol 2003; 10: 301-6.

10 Brooks PM, Lapsley HM, Butt DB. Medical workforce issues in Australia: 'tomorrow's doctors - too few, too far'. Med J Aust 2003; 179: 206-8. 


\section{Appendix I}

Head of department questionnaire: questions for Neurology Units

(please fill a separate form for each hospital)

\section{Hospital Background Information}

Name and location of Hospital(s)

Total number of beds in hospital

Estimated population within catchment area

Name of Head of Neurology Department

Number of dedicated neurology beds

Average number of neurology inpatients

Do you have neurosurgery on site? $\quad$ Yes/No

Do you have neurophysiology on site? $\quad$ Yes/No

\section{Neurology Unit Activity Profile (please use 2004-2005 figures if possible)}

9 Number of Neurology CWS p.a.

10 Case weight for all Neurology (not individual DRG's)

11 ALOS - all Neurology

\section{Neurology Unit Staffing Profile}

Number of VMOs (FTE)

Number of Staff Specialists (FTE)

Number of Advanced Trainees (FTE)

Number of Basic Trainees (FTE)

Number of RMOs (FTE)

Number of interns (FTE)

Number of CMOs (FTE)

Others? (please specify)

\section{Rostering Arrangements}

- advanced trainee

- basic trainee

- RMO

- Intern

- $\mathrm{CMO}$

- Other (please specify)

21 If any, what does the specific neurology on call roster for JMOs look like?

- advanced trainee

- basic trainee

- RMO

- intern

- $\mathrm{CMO}$

- Other (please specify)

22 Estimation of the number of hours/week of overtime required of JMOs

- advanced trainee

- basic trainee

- RMO

- intern

- $\mathrm{CMO}$

- Other (please specify)

\section{Out Patient Clinics}

23 Total number of public general neurology outpatients/week

24 Number of junior staff (FTE) assisting at these clinics

- advanced trainee

- basic trainee

- RMO

- intern

- $\mathrm{CMO}$

- Other (please specify)

Total number of specialist neurology outpatients/week (including neurophysiology clinics) 
Appendix 1 Coninued

26 Number of junior staff (FTE) assisting these clinics

- advanced trainee

- basic trainee

- RMO

- intern

- $\mathrm{CMO}$

- Other (please specify)

Thank you very much indeed.

If you have any queries, please telephone Christian Lueck on 0439334784.

Please e-mail responses to christian.lueck@act.gov.au, or fax them to 0262444629.

\section{Appendix II}

\section{Junior Staff Questionnaire}

\section{ANZAN survey of Advanced Trainees}

I need a bit more information to complete this survey, and would be most grateful if you could help me by providing the following information. All information will be treated confidentially, and I will be de-identifying individual hospitals as far as I possibly can for the purposes of presentation.

Name:

E-Mail address:

Hospital:

Inpatients. On average:

How many neurology inpatients are you personally responsible for?

How many consults do you see each week?

Clinics. On average:

How many general neurology clinics do you get to each week?

How many specialist neurology clinics do you do each week?

What specialist clinics do you have access to?

Electrophysiology. On average:

How many NCS/EMG clinics do you attend each week?

Do you think the teaching provided in NCS/EMG is adequate?

How many EEGs do you report each week?

Do you think the teaching provided in EEG is adequate?

On Call: On average, over and above the 'basic' (40 hour!) working week:

How many hours of general medical on-call do you do each week?

Tell me your roster arrangements if this is easier

How many hours of specific neurological on-call do you do each week?

Tell me your roster arrangements if this is easier

How many unrostered hours do you work each week?

How many of these are paid?

Thank you very much indeed. Please hand this back to me a.s.a.p. Christian Lueck 